\title{
Erratum to: Relationship between bone mineral density, bone turnover markers and homocysteine, folate and vitamin B12 levels in postmenopausal women
}

\author{
Berna Halıloglu • Fehime Benli Aksungar • \\ Erdin Ilter · Hakan Peker · Figen Temelli Akın • \\ Nilgun Mutlu $\cdot$ Umit Ozekıcı
}

Published online: 16 April 2010

(C) Springer-Verlag 2010

Erratum to: Arch Gynecol Obstet (2010) 281:663-668

DOI 10.1007/s00404-009-1297-4

Unfortunately, one of the co-author names (Nilgun Mutlu) was missed in the published online as well as in the printed version of the article. The correct author group should be

"Berna Halıloglu, Fehime Benli Aksungar, Erdin Ilter, Hakan Peker, Figen Temelli Akın, Nilgun Mutlu, Umit Ozekıc1”
Co-author Nilgun Mutlu's address is: Department of Biochemistry, Faculty of Medicine, Yeditepe University, Istanbul, Turkey

The online version of the original article can be found under doi:10.1007/s00404-009-1297-4.

B. Halıloglu · E. Ilter · F. T. Akın · U. Ozekıc1

Department of Obstetrics and Gynecology, School of Medicine,

Maltepe University, Istanbul, Turkey

F. B. Aksungar

Department of Biochemistry, School of Medicine,

Maltepe University, Istanbul, Turkey

H. Peker

Gediz State Hospital, Kutahya, Turkey

B. Halıloglu $(\square)$

Barbaros Mah. Dereboyu Cd, Starland D1-1 Blok,

Daire:101 Bat1 Atasehir, Istanbul, Turkey

e-mail: bernadr23@hotmail.com; bernahaliloglu@yahoo.com

N. Mutlu

Department of Biochemistry, Faculty of Medicine,

Yeditepe University, Istanbul, Turkey 